\title{
A Flexible and Economical Field Microscope
}

\section{Glenn Shipley* and Robert Hoelter}

Sibylife Laboratories, 6718 N Mozart St., Chicago, IL 60645

*glennshipley@gmail.com

\section{Introduction}

The problem. For any serious microscopist, there are times and places where you would like to have a field microscope at your fingertips, but procuring one is expensive, difficult, or impossible. For example there are places you can go in the USA, and even in other nations on the planet, where you are not allowed to remove any materials or specimens without special permission. As unforeseen opportunities for travel arise, that permission may not be easy or quick to obtain. It would be nearly impossible for amateurs or hobbyists to get such permission and very difficult even for professionals or academics traveling on short notice. Examples of such sites are national parks and World Heritage Sites. Besides the problem of not being allowed to take things out, there is the problem of getting instruments in these places in the first place, or negotiating equipment through airport security.

In this article we propose a solution to these problems: a lightweight portable field kit centered on an inexpensive brightfield light microscope. There are still a few "field microscopes" around, and some very interesting new ones on the horizon (as we describe in the concluding section), but they are rare, presently unavailable, too expensive for the hobbyist or academic on a budget, or somewhat limited in accessories.

Requirements for a field microscope. It is useful to begin with a list of requirements or expectations anyone should have for a completely versatile, optical field microscope, particularly one that does not break the personal or institutional piggy bank of traveling professionals, hobbyists, and citizen microscopists. Such a list of criteria would include:

1. Portability - it should be small and light enough to fit in a backpack or luggage that can pass through airport security;

2. Rugged construction - preferably an all-metal body and parts;

3. Standard focus - using rack-and-pinion coarse adjustment and having some way to stop gravitational tube drift;

4. Standardized optics - it should take standard RMS-threaded objectives and $23 \mathrm{~mm}$ oculars that fit most brightfield microscopes produced by major manufacturers and provide for a normal range of magnification and resolution up to $600 \times$ or $800 \times$;

5. Camera capability - it should be capable of ordinary on-site photomicroscopy to record images of non-removable or biologically fragile specimens;

6. Usable under a wide variety of light conditions - it should be able to use both on-location available light sources and small battery-powered LED light sources;

7. Illumination flexibility - it should be capable of on-site brightfield, darkfield, Rheinberg, polarization, oblique, and epi-illumination techniques;

8. Environmental versatility - it should be able to be used on location in somewhat challenging temperature and climate conditions without worry of expensive damage or loss;
9. Availability - it should be a basic instrument not likely to be dropped from inventory by manufacturers;

10. Age neutrality and professional flexibility - it should be usable not only by professionals, but by amateurs and children;

11. Economy - it should not be prohibitively expensive in case of loss, theft, or damage.

The following sections describe a microscope that satisfies these criteria and a set of accessories comprising a suitable field kit.

\section{Materials and Methods}

Shop inspection microscope. Figure 1 shows a suitable microscope manufactured and sold today as a "shop inspection microscope." It is readily available through internet outlets for less than $\$ 100$. The example shown is a Chinesemanufactured Amscope (SKU: H100) offered regularly on eBay, but nearly identical models are available elsewhere, for example, from PrecisionWorld and MicroscopeNet. The rugged body is made of metal (meeting criteria \#1 and \#2), the only plastic part being the handle of the rack-and-pinion coarse adjustment (meeting criterion \#3), and yet the overall

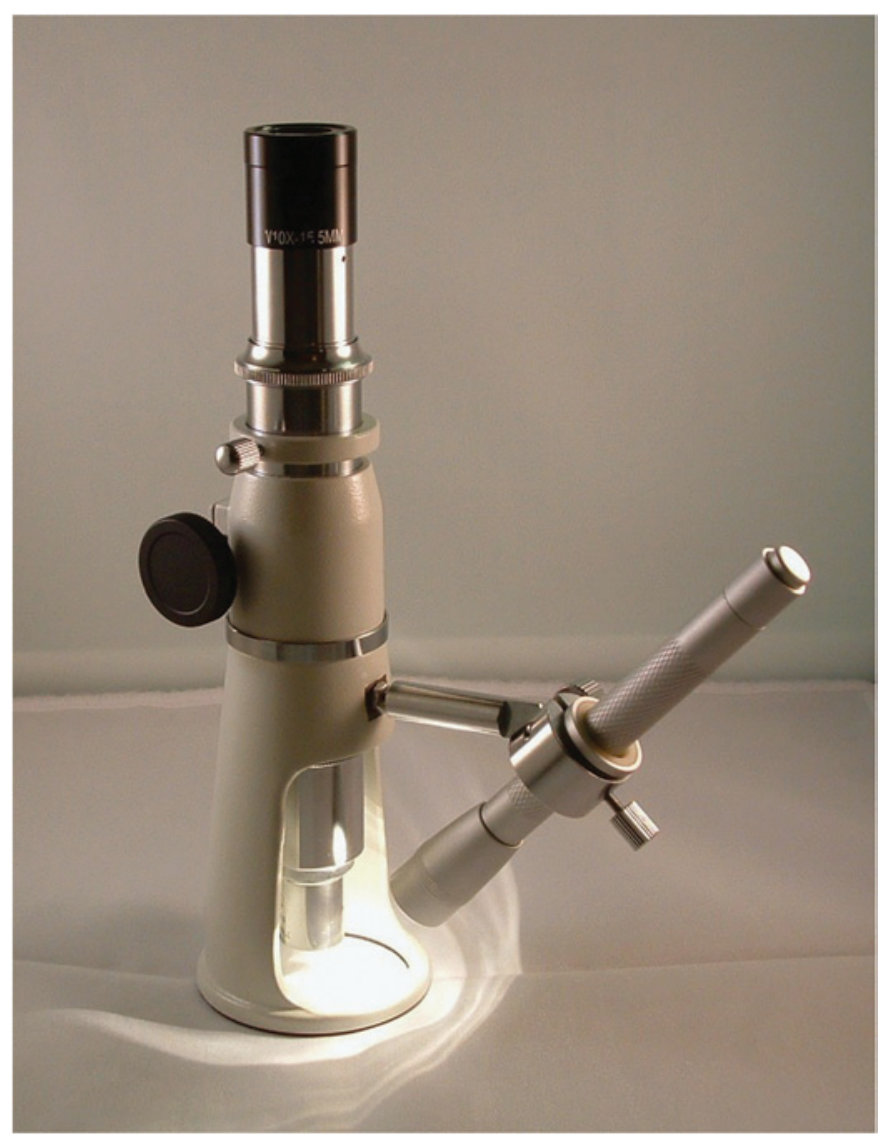

Figure 1: The typical shop inspection microscope. The flashlight on the extension arm is adjustable and both are easily removed. 

weight of the microscope as pictured, with lenses and flashlight with two AA batteries, is only 1 pound, 6 oz. (614 grams). Its overall sturdiness and simplicity of design (it is about as basic as a compound microscope can get) meet the portability and ruggedness criteria.

This device is generally offered as pictured in Figure 1, with the removable flashlight attachment, a standard $10 \times$ eyepiece, and either a $4 \times$ or $10 \times$ objective. Both lenses are industrystandard; the widefield eyepiece fits in a $23 \mathrm{~mm}$ body tube, and the achromat objective is RMS-threaded and fits on the nosepiece of any standard microscope. This meets criterion \#4. The eyepiece comes with a measuring reticle calibrated as a line divided into 100 parts so that with a $10 \times$ objective, specimens in the field of view can be directly measured with reasonable precision in hundredths of a millimeter.

Most models of this microscope come equipped with a sliding collar on the body tube, which can be tightened with a thumb-screw, setting it to a fixed height to avoid focal drift during photography or damage to an objective or specimen from focusing too far downward. The collar ensures photographic stability even with heavier cameras, thus meeting criterion \#5. The epi-illuminating flashlight slides into a socket on a cantilevered arm that is easily detached for storage and transport.

This microscope was designed for use in machine shops and other places where handy portability for inspecting materials and measuring tight tolerances is required. Illumination of surfaces from above the specimen is its primary purpose. That utility ensures that it is not likely to be a discontinued model (meeting criterion \#9). But for field microscopy, the rugged appeal of this simple microscope is offset by its awkwardness for transmitted light applications, with no obvious way to position a glass slide under the objective.

Microscope stage platform. The authors incorporated transmitted light capability and easy slide positioning by designing a stage platform to be made out of readily available carpentry materials: wooden board, dowels, wood screws, insulator strips, and metal washers. Fabrication required only a table saw, a drill press, and a router. These materials are available at any lumberyard or home repair center, and, if not personally owned, the tools can be used at a hobby center or high school woodshop. A little woodshop training or help from a skilled woodworker is helpful. In my case, I had the basic tools but also had significant help from co-author Robert Hoelter, who is an experienced tool-anddie-shop technician.

The basic idea is modeled on Quekett's design for a single-lens dissection microscope [1] illustrated in Figure 2. The Quekett design is a simple platform with four legs and a hole in the table surface to allow light from below to shine up through a specimen. The authors modified this design so that the stage itself elevates a compound "shop inspection" microscope on a pair of rails running along two edges of a rectangular lower plain on which a microscope slide can be positioned (see Figure 3). The microscope is held in position by a pair of insulation strips with rubber edging, running above the rails. These allow the microscope to be slid into position above the central light hole while stabilizing the microscope from lateral movement or tipping over during use.

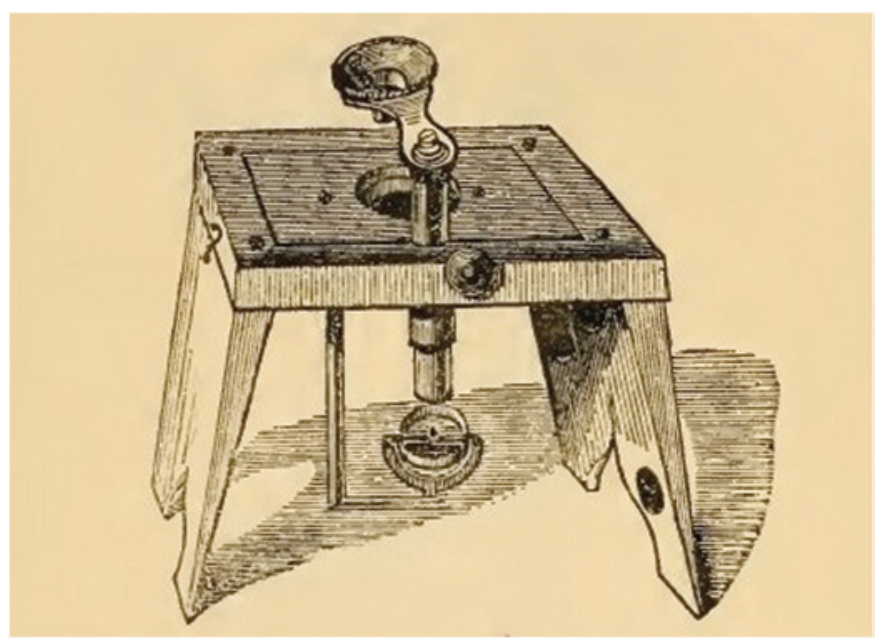

Figure 2: Quekett's single-lens dissection microscope and platform [1].

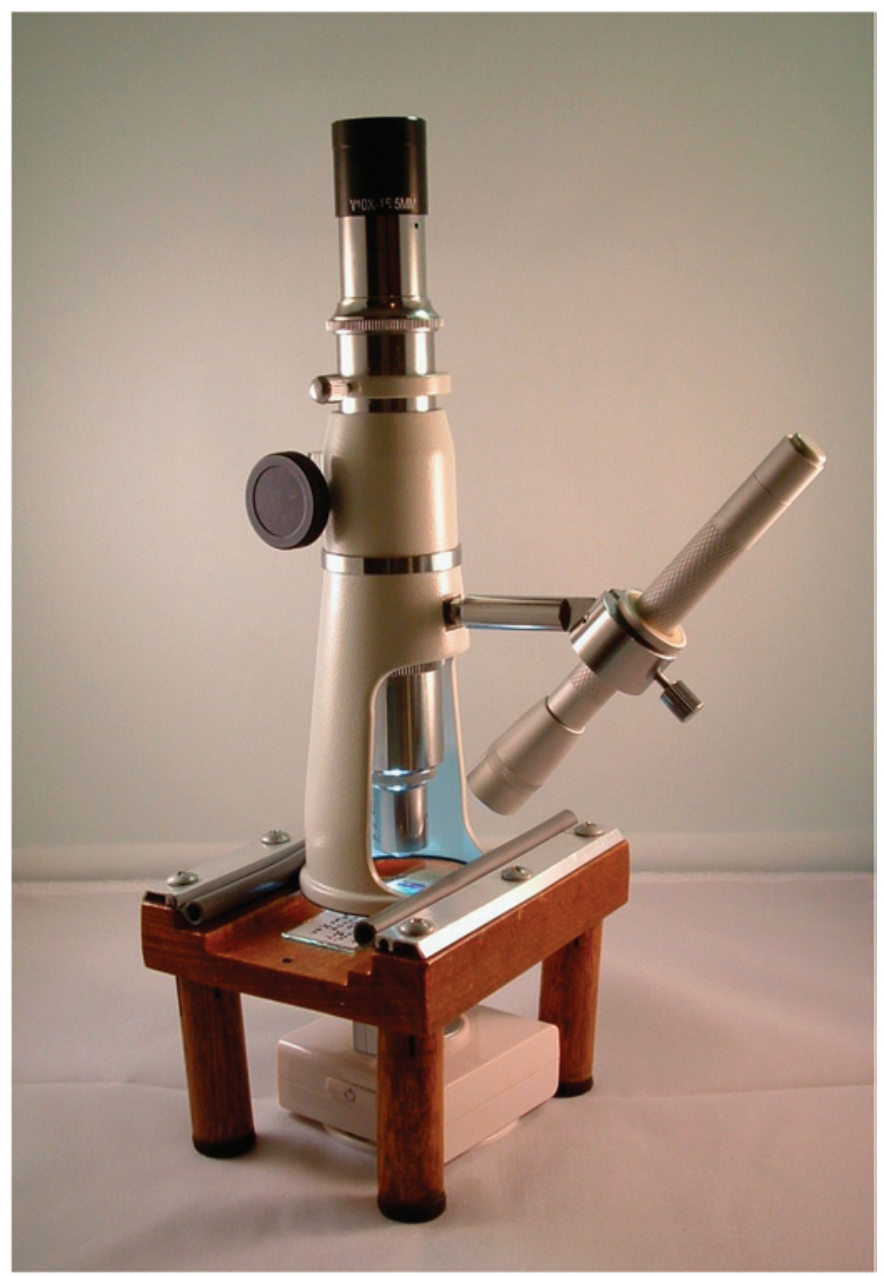

Figure 3: Do-it-yourself platform stage for the shop inspection microscope.

The stage is fashioned from standard $1 " \times 4$ " wood board (preferably a hardwood, but even PVC boarding would work) cut to a 5 " length. Using a router, the centered section stripe is cut down the length of the board segment, $1 / 4$ " deep $\times 21 / 2$ " wide. This is the exact outer diameter of the circular bottom of the shop-inspection microscope stand. Then a 


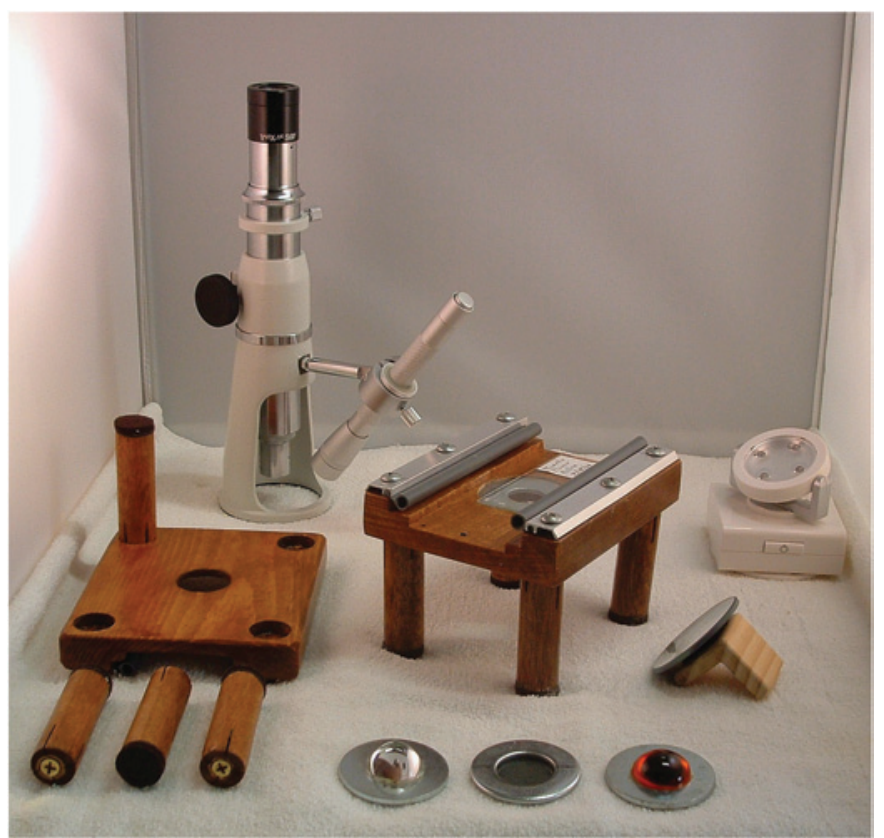

Figure 4: Shop inspection microscope and platform stage with a few accessories: sub-stage condenser, polarizing filter, Rheinberg darkfield filter, and sub-stage mirror.

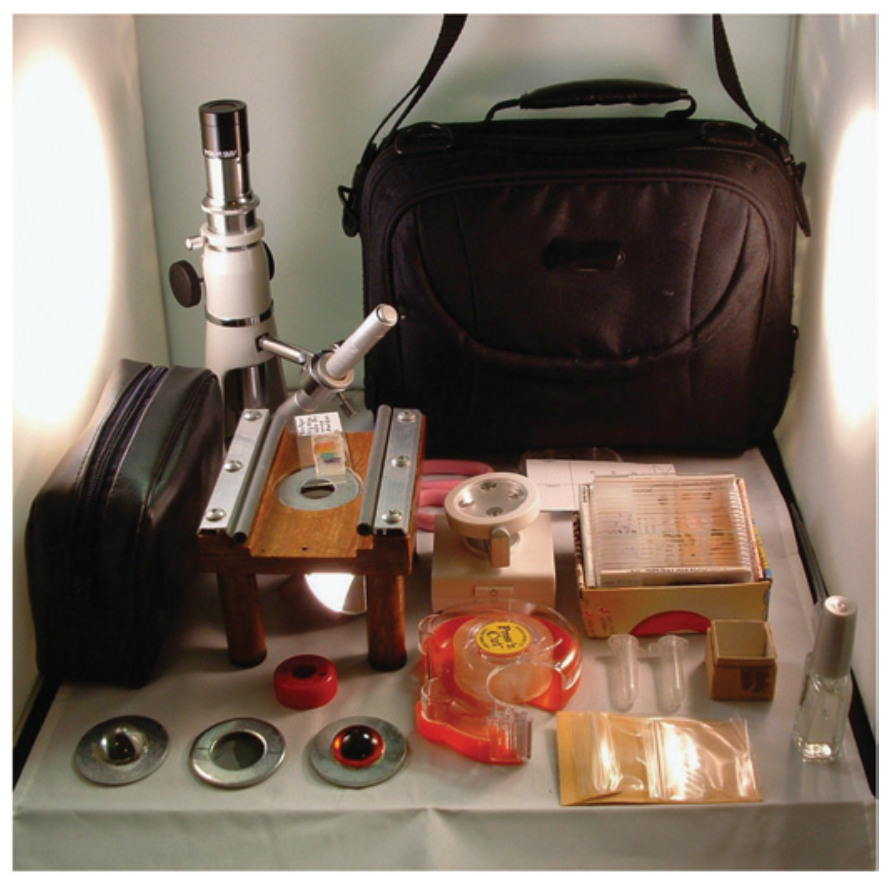

Figure 5: A typical field kit. All this and more fits easily into a camera or CD/DVD carrying bag like the one pictured.

second routing, centered on the first, creates a plane lower by another $1 / 4^{\prime \prime}$, and cut below and $2^{\prime \prime}$ wide, just narrower than the first cut thereby creating the slide specimen plane.

Using a drill press, two concentric holes are cut into the center of this stage: the first 1 " in diameter going all the way through the wood and the other a "well" $13 / 4$ " wide and surrounding it. The central complete hole is easily cut using a standard 1" drill bit, but the 1/4" deep recessed outer "well" requires a bit of customization, which I leave to the carpentry imagination and skills of the reader. The idea of the central

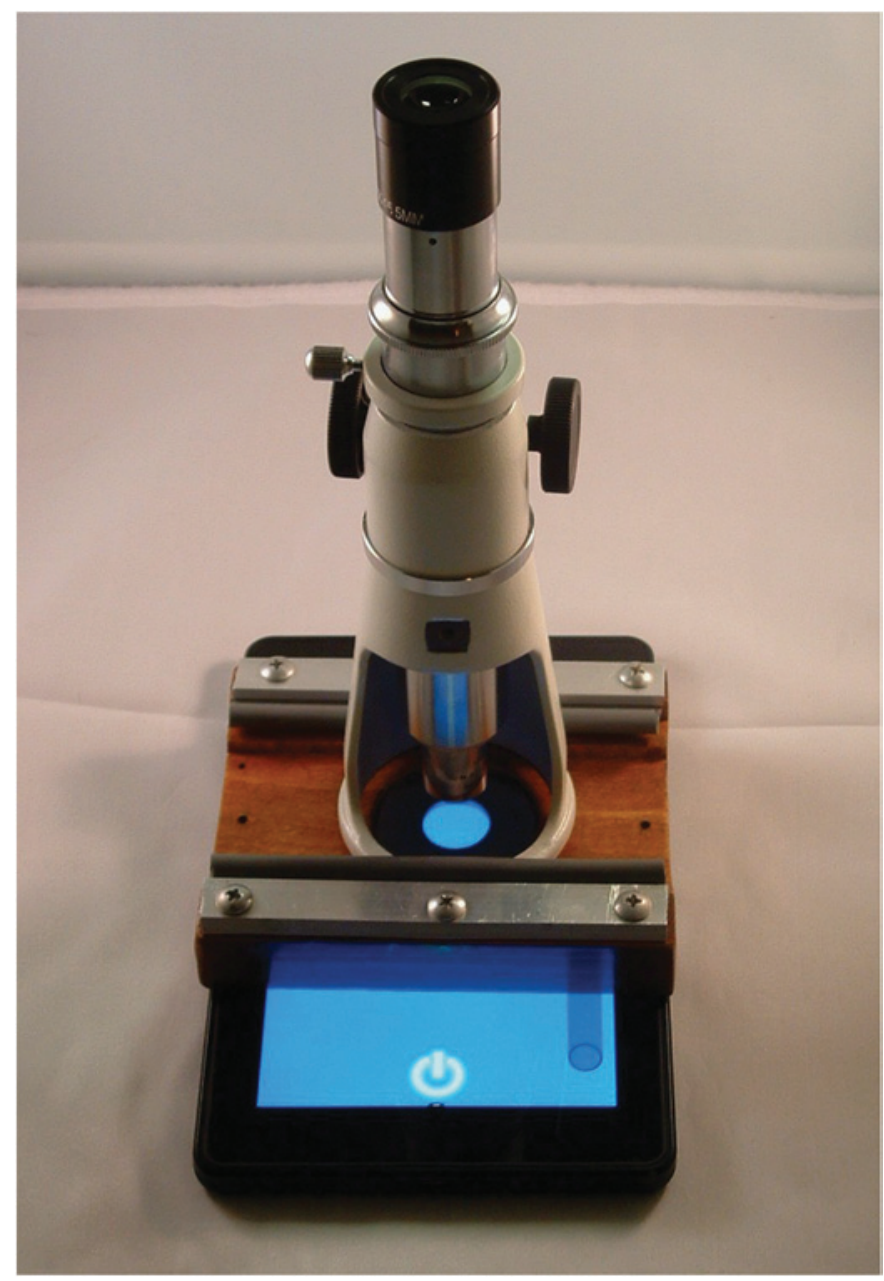

Figure 6: Flashlight app, running on a Kindle Fire, employed as an illumination source for the field microscope. This works best if the stage is placed directly on the screen. The photo shows a blue screen to illustrate the color flexibility of the app, but it works as well as a white light source.

hole is to allow light to shine up from below the stage when operating in transmission mode. Finally, the segments of insulation strip are cut and mounted along the two upper edges of the stage. They should be positioned so that only the rubber portion covers the microscope rails, as shown in Figure 3.

To hold the stage above a light source, the authors fashioned four legs from standard 3/4" diameter dowels cut to size, and then they drilled incomplete holes on the four corners of the underside of the stage as sockets for them. One of the authors (Robert Hoelter) invented a modified form for these legs with two crosscut slots at one end of each of them and a wood screw placed at the intersection of the slots to adjust tension to hold the legs firmly in position. One-inch self-sticking circular felt pads at the other end finish the leg preparations. Sanding and finishing the wooden parts with urethane varnish is advisable to allow easy cleanup from specimen spillage and smooth movement of the slides and microscope stand.

When fully assembled, a light source like an LED "puck" light can be positioned under the stage platform for brightfieldtransmitted light work. The author has also fashioned a substage 


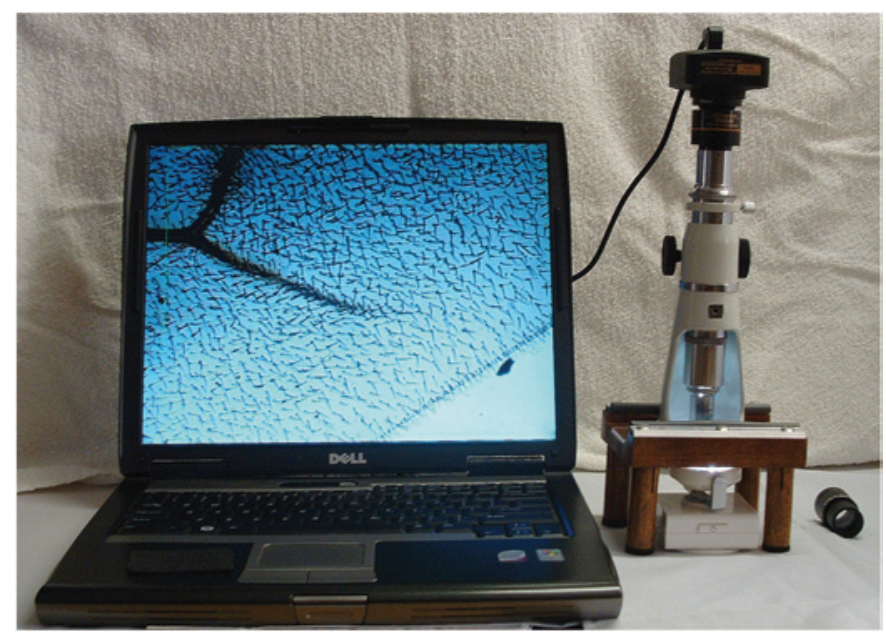

Figure 7: Field microscope with Amscope MU300 digital eyepiece camera, shown attached to a laptop computer via a USB cable.
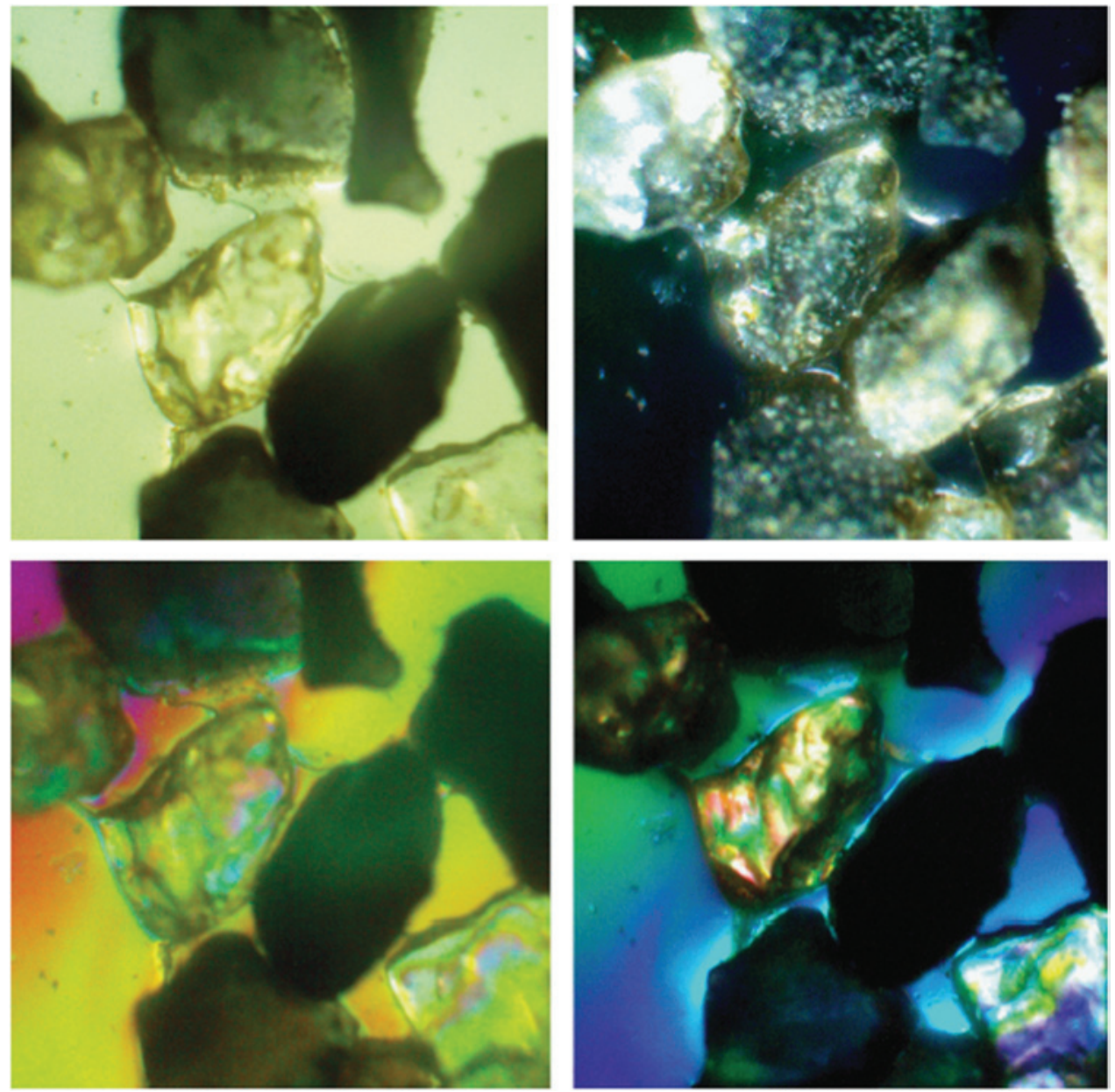

Figure 8: Example images of sand grains from Wyoming taken with the shop-inspection field microscope. Clockwise from upper left: sub-stage transmitted light, oblique epi-illumination, cross-polarized light, cross-polarized light with wave plate (cellophane wrap). All images were taken with an Amscope eyepiece camera and 10x objective. Image width $=1.0 \mathrm{~mm}$

mirror on a wooden mount that can be positioned between the legs for use with available light, as shown in Figure 4 below.

Accessories. The versatility provided by accessories to this setup increases its utility in the field. Figure 4 shows the assembled field microscope on the stage platform along with a number of accessories arranged in front of it. These include a substage condenser lens, polarization filter, and darkfield Rheinberg filter-anything that can be mounted on a $13 / 4 "$ metal washer and placed in the well surrounding the central light hole.

Also pictured are various lighting arrangements, including oblique epi-illumination provided by the attachable flashlight (very helpful for surface examination of opaque or thick specimens like sand or wood), but also LED and available transmitted light sources from below the stage. This exceeds the requirement outlined in criteria \#6 and \#7.

Easily and quickly assembled and dismantled, all this and much more can be fit into a convenient carrying case like a camera bag or the CD/DVD bag pictured in Figure 5. I have packed a $1 / 2$ gross box of standard $1 " \times 3$ " glass slides and $23 \mathrm{~mm}$ square coverslips in this field case along with dozens of other specimen-collecting and holding devices, like $2 " \times 2$ " plastic baggies with zippers, small plastic capped centrifuge tubes, plastic Pasteur pipettes, small bottles of isopropyl alcohol, and lens cleaner. The whole $10^{\prime \prime} \times 8^{\prime \prime} \times 5^{\prime \prime}(24 \times 20 \times 12 \mathrm{~cm})$ case fully loaded weighs $5 \mathrm{lbs}(2.3 \mathrm{~kg})$, and it has a shoulder strap for easy carriage in the field. I have passed through the security check points of many airports with this field kit, and while it inevitably gets me pulled aside for questioning ("What IS this thing-a drill?"), it has never caused a serious problem or delay in getting to my scheduled flight on time.

Smartphone light sources. I recently discovered a free application ("app") written for the purpose of turning a smartphone or tablet into a flashlight or "torch" to find things in the dark. What is interesting from a microscopy point of view is that this app allows the user to adjust not only the brightness of the screen-sourced light, but also to choose an enormous range of colors, also adjustable for intensity. If used as a light source with the field microscope and stage described above, an amazing range of lighting is made possible. The arrangement is illustrated in Figure 6.

To make use of this app, the platform stage, without legs attached, can be set directly on top of a smartphone or tablet. I have used it quite effectively with my Kindle Fire. Some electronic phones and tablets (including the Kindle Fire) even come with a screen that provides linearly polarized light. This can be used with the other non-white colored background light choices, giving a huge range 
of color, polarization, and light intensity combinations under field conditions.

Digital camera. Although the shop inspection microscope is capable of supporting heavier cameras, adapters for mounting them would offer a challenge, and traveling light would seem to require something smaller and more portable. An Amscope MU300 3 MP digital eyepiece camera with FMA050 adapter is shown in Figure 7. The camera mounts in place of the eyepiece and attaches by USB to a laptop computer. This limits portability, of course, but with current generations of laptop tablets and such, this is not a significant obstacle to overcome. Example images taken with this setup are shown in Figure 8.

\section{Discussion}

The practicing field microscopist is not completely without recourse to alternative field microscopy equipment at the present time, There are commercially manufactured microscopes currently advertised as "field microscopes," and the patient shopper can still find an occasional "vintage" Swift FM-series field microscope for sale on eBay. In a previous article in this magazine (B. Cline et al., "Design and Validation of a Low-Cost Microscope for Diagnostics in the Developing World," [2]), the authors propose a design for a versatile and lightweight field microscope, but to this author's knowledge that microscope is still not commercially available. Other new developments also bear watching, such as Manu Prakash's amazing origami "Foldscope" (see [3] and www.foldscope.com), which is currently undergoing beta testing but is still not generally available for sale to interested field microscopists. Other commercial field microscopes currently being sold are expensive and still require more careful handling than field conditions may allow.

The shop inspection microscope described in this article is widely and readily available right now and promises to be for some time to come. The do-it-yourself custom stage platform can be made and assembled easily and cheaply and is quite versatile and rugged for fieldwork. This combination meets all the basic requirements listed at the beginning of this article.

Besides fieldwork, this microscope is an excellent introductory instrument for students and hobbyists. It gives them a "hands on" sense of what is involved in a truly basic microscope with a form that is reminiscent of the original compound microscope of Robert Hooke and other early seventeeth- and eighteenth-century microscopists. Rather than being faced with a complicated and expensive instrument, novices are quickly engaged with a simple and inexpensive one that they can handle and control, which uses standard lenses that enable them to clearly see an enormous diversity of microscopic forms. Even after someone moves on to a more expensive and sophisticated professional stand, it will remain useful as a field instrument or a hand-me-down first microscope gift to another beginner.

The authors have often packed additional standard eyepieces and objectives in this field kit (for example, a $15 \times$ widefield ocular and $40 \times$ and $60 \times$ objectives), and we have sometimes found it handy to use a "divisible" $10 \times$ objective (Bausch \& Lomb), where the front section of the objective unscrews to allow it to be used as a $5 \times$ hand lens. The only limitation to this scope is that it is unsuitable for higher-power work requiring oil-immersion objectives in the $100 \times$ range, which would be difficult to focus without a fine adjustment. However the authors have used it quite effectively with a $60 \times$ dry objective and a $15 \times$ ocular, which approaches that level of magnification (if not resolution). But other than that, the flexibility of this stand is limited only by the microscopist's imagination!

\section{Conclusion}

For about $\$ 100$ and change, a credible field microscope kit can be fashioned from easily available parts. In this article the authors have presented a flexible and durable system using standard optical components and home-customized parts. It meets all the relevant requirements outlined at the beginning of the article. Its economy and portability recommend it for anyone with a need for doing field microscopy on a limited budget.

\section{References}

[1] WB Carpenter, The Microscope and Its Revelations, $5^{\text {th }}$ Edition, Lindsay and Blakiston, Philadelphia, 1875, fig. 32, p. 80. Various editions of this classic work are available for free on-line download from the Internet Archive website.

[2] B Cline et al., Microscopy Today 17 (2009) 16-19.

[3] Microscopy Today Innovation Awards, Microscopy Today 22 (2014) 48-53.

\section{Precision, Speed, Stability}

\section{NANO-POSITIONING FOR MICROSCOPY}

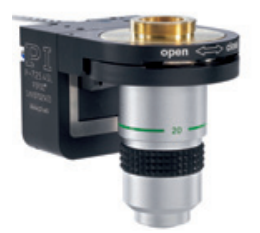

High-speed nanofocus $<1 \mathrm{~nm}$ resolution
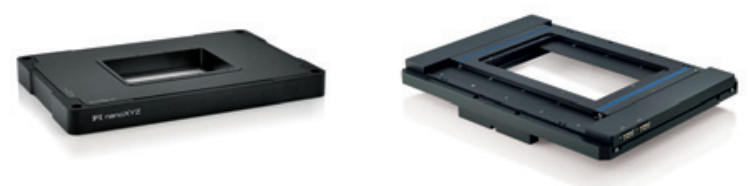

$X Y Z$ flexure stage $<1 \mathrm{~nm}$ resolution

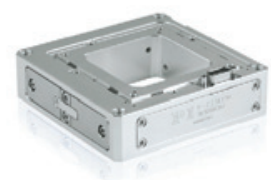

$X Y Z$ stage for

High-stability XY piezo motor stage, $100 \mathrm{~mm}$

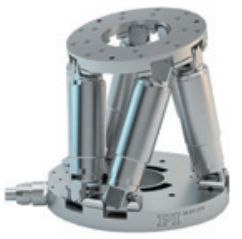

6-axis precision positioner 


\section{Microseopy

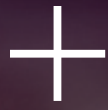 Fluorescence}

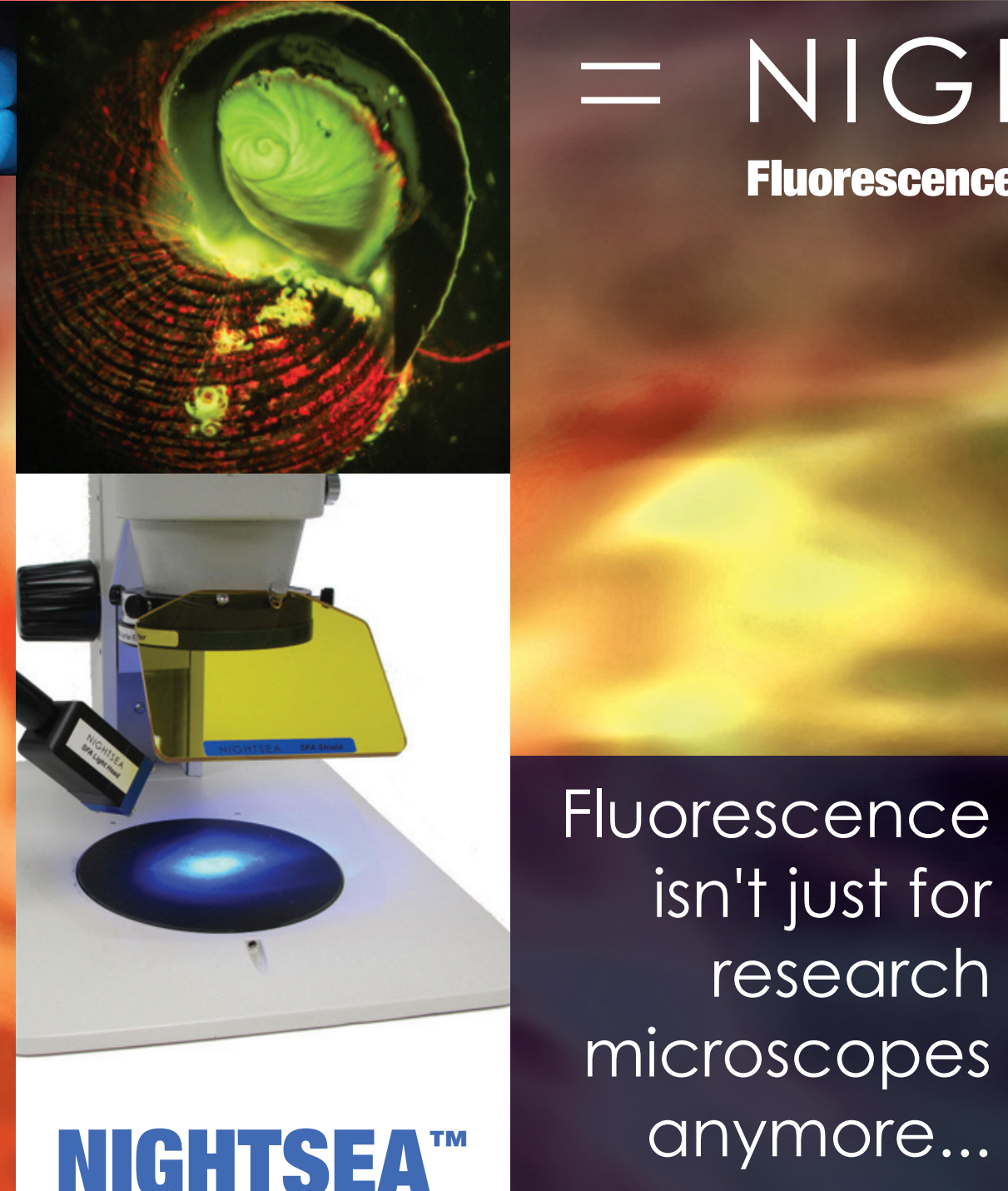

Stereo Microscope Fluorescence Adapter

Adapt your existing lab stereo microscopes for fluorescence

The NIGHTSEATM Stereo Microscope Fluorescence Adapter adapts just about any stereo

microscope (dissecting microscope) for fluorescence with no modification to the microscope

itself. The modular design lets you easily switch between several different excitation/emission combinations to work with a variety of fluorescent proteins and other fluorophores. There are now five different excitation/emission combinations available, plus white light.

\section{Applications}

Quick screening of your fluorescent genotypes - Drosophila, zebrafish, C. elegans,...

Genotype sorting

Fluorescence-aided dissection, injection, or micromanipulation
Freeing up your research-grade fluorescence microscopes for more demanding work

New faculty start-up budgets

Bringing fluorescence into teaching laboratories

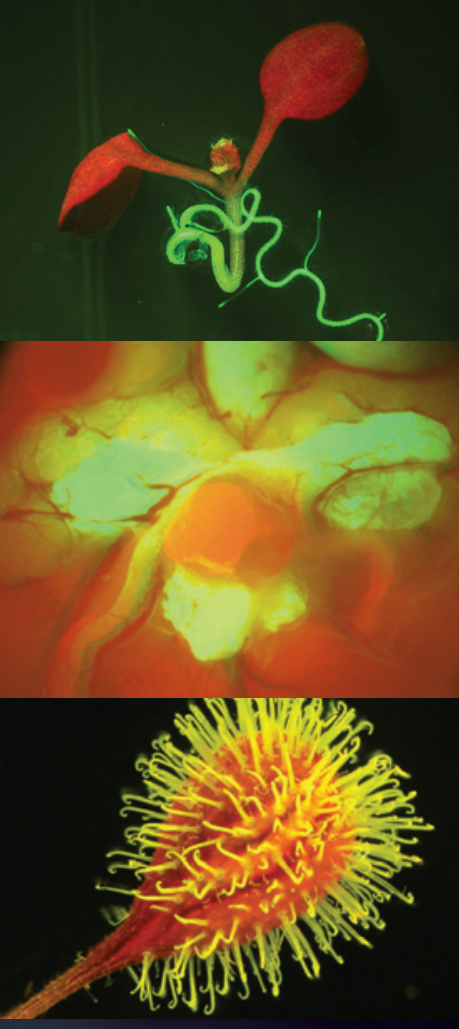

CONTACT US FOR MORE INFORMATION...

\section{EMS has itt}

\section{Electron \\ Microscopy \\ sciences}

P.0. Box 550 - 1560 Industry Rd.

Hatfield, Pa 19440

Tel: (215) 412-8400

Fax: (215) 412-8450

email: sgkcck@aol.com

or stacie@ems-secure.com

www.emsdiasum.com 


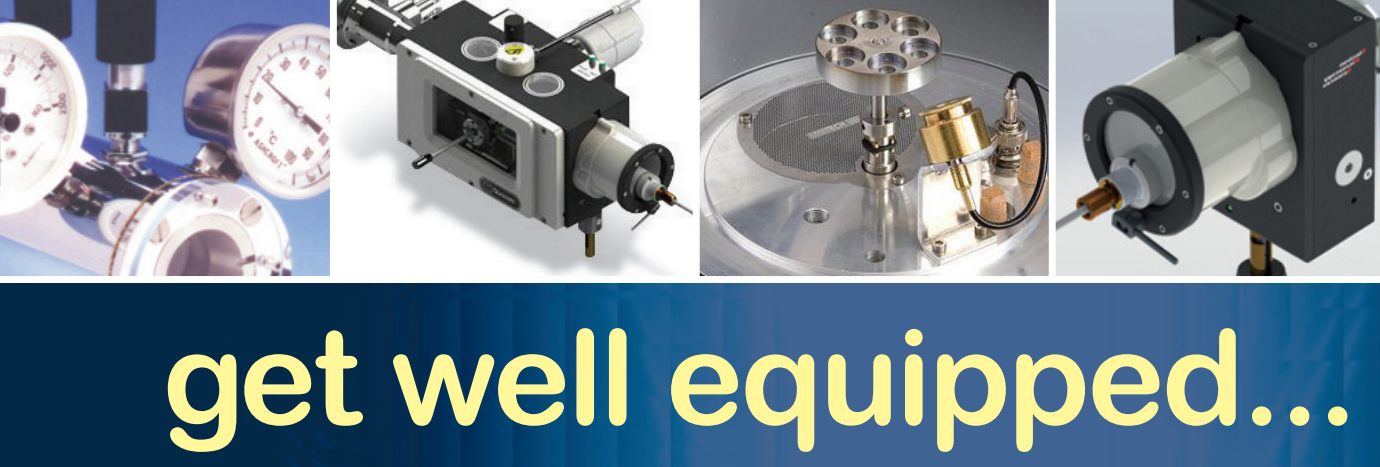

EMS is committed to providing the highest quality vacuum equipment with competitive pricing, prompt delivery and outstanding customer service.

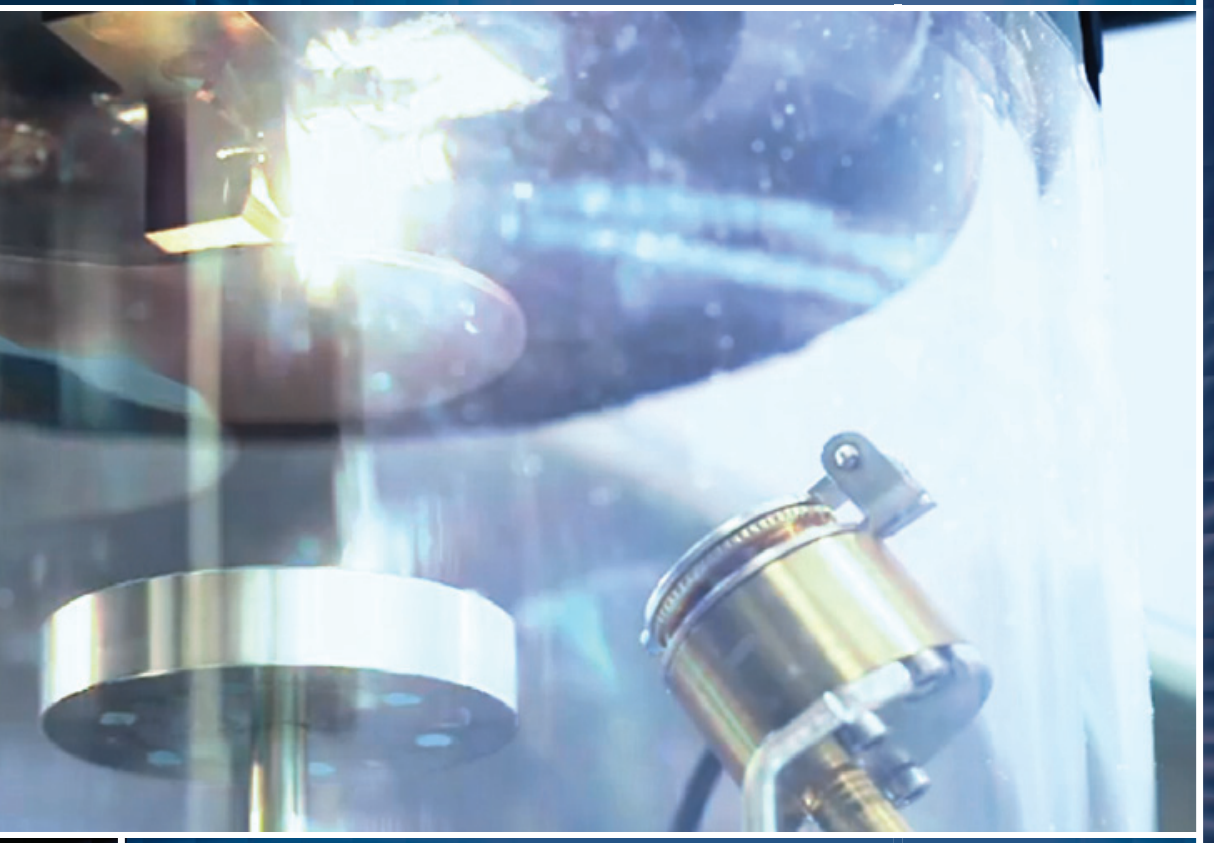

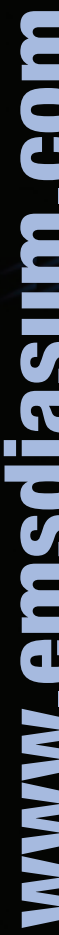

\section{more than just products...}

Both our Full Line Catalog and our website are loaded with supplemental information for electron microscope specimen preparation equipment, including articles and video reviewing electron microscope preparation techniques, such as...

- Sputter Coating Techniques and Applications

- Silver as a Removable Coating for Scanning Electron Microscopy

- Carbon Coating Techniques and Applications

- Plasma Etching and Ashing Techniques and Applications

- A summary of the Critical Point Drying Method

- Freeze Drying Principles

- Cryo-SEM — the Advantages

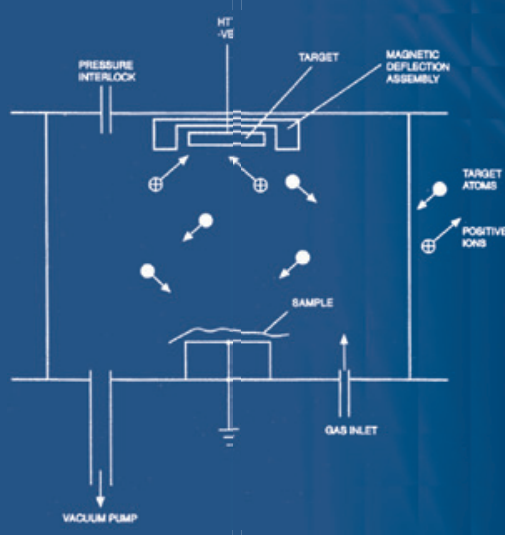

Our extensive line of High-End Vacuum

Equipment and Accessories includes...

\section{Cooling Stages}

Recirculating Heaters and Chillers

Sputter Coaters

SEM/TEM Carbon
Coaters

Vacuum Evaporators (Large Chamber)

Critical Point Dryers

Freeze Dryers

RF Plasma Etchers/

Plasma Reactors

Cryo-SEM Preparation Systems

NEWH Specimen Transfer Systems

\section{CONTACT US FOR} MORE INFORMATION... EMS has it!

\section{Electron \\ Microscopy sciences}

P.O. Box 550 • 1560 Industry Rd.

Hatfield, Pa 19440

Tel: (215) 412-8400

Fax: (215) 412-8450

email: sgkcck@aol.com

or stacie@ems-secure.com

www.emsdiasum.com 